\title{
A Clinical Study of Steroid Induced Dermatoses
}

\author{
Parajuli S', Paudel U1', Poudyal AK², Pokhrel DB ${ }^{1}$
}

${ }^{1}$ Department of Dermatology and Venereology; ${ }^{2}$ Department of Community Medicine and Public health, Maharajgunj Medical Campus, Maharajgunj, Institute of Medicine, Tribhuvan University, Kathmandu, Nepal

\begin{abstract}
Introduction: Steroid induced dermatoses on face are one of the common presentations in Dermatological practice.

Objectives: 1) Understand the clinical patterns of adverse effects of long term abuse of topical steroid on face and 2) Assess the factor which promotes its abuse.

Materials and Methods: This was a descriptive exploratory cross-sectional study carried out from December, 2013 through November, 2014. A total of 39 patients fulfilling the inclusion criteria were enrolled into the study. All the study variables were recorded using preformed structured questionnaire and analyzed.

Results: The following effects of steroid abuse on face were seen: pruritus (38.5\%), burning (15.4\%), eythema (74.4\%), telangiectasias (66.7\%), acneiform eruptions (59\%), comedones (35.9\%), xerosis $(55.1 \%)$, photosensitivity $(51.3 \%)$, rebound phenomenon (38.5\%) and others (38.5\%). Most of them used steroids on recommendation of their friends $(38.5 \%)$ and pharmacists (20.5\%). All of them used steroid for different dermatoses on their face.

Limitations: This is a hospital-based small-scale study and might not be true picture of problem in the community.

Conclusion: Long term use of steroid on face results in different clinical presentations. Most of the patients used steroid on recommendation of their friends facilitated by easy availability of the drug over- the -counter.
\end{abstract}

Key words: Comedones; erythema; non prescription drugs; papules; pustules; rosacea; steroids

\section{Introduction}

T opical corticosteroids are very important drugs in dermatological practice. When these drugs are prescribed rationally they can be of enormous benefit and clinically significant side effects are rare. However, injudicious use of steroids for long term might results in various side effects which increases the morbidity due to cutaneous side effects as well as the economic burden of treating the steroid induced dermatoses..$^{1,2}$ Steroid induced dermatoses are common presentations in Dermatology Outpatient Department of different hospitals of Nepal and are one of the important causes of socioeconomic burden as the condition is caused due to lack of strict drug use policy or regulation act, ignorance of its proper use and tendency of patients for self-medication commonly guided by drug marketing people, pharmacists and patients friend/ relatives. $^{3}$ Since the topical steroids dramatically

\footnotetext{
Address of Correspondence:

Dr. Sudip Parajuli

Assistant Professor

Department of Dermatology

Maharajgunj Medical Campus, Tribhuvan University

Maharajgunj, Kathmandu, Nepal

E-mail: sudipparajuli@gmail.com
}

improves the majority of dermatoses temporarily, there is tendency to apply these drugs again and again by the patients, which in long run leads to variety of adverse effects. Though a common affliction encountered in Dermatology practice, till date, there are only few studies in our country on steroids induced dermatoses. ${ }^{4,5}$ This study was an attempt to assess the clinical patterns of abuse of topical steroids on face and the factors which promoted the use of these steroids in our population.

Submitted: $15^{\text {th }}$ January 2018

Accepted: $28^{\text {th }}$ February 2018

Published: $21^{\text {st }}$ March 2018

\section{How to cite this article}

Parajuli S, Paudel U, Poudyal AK, Pokhrel DB. A clinical study of steroid induced dermatoses. Nepal Journal of Dermatology Venereology and Leprology. 2018;16(1):12-6. doi: http://dx.doi. org/10.3126/njdvl.v16i1.19397.

\section{(c) (i)}

Licensed under CC BY 4.0 International License which permits use, distribution and reproduction in any medium, provided the original work is properly cited. 


\section{Materials and Methods}

This descriptive cross-sectional study was carried out in the Department of Dermatology, Tribhuvan University Teaching Hospital, Kathmandu, Nepal for a period of one year from December, 2013 through November, 2014. A total of 39 patients with steroid induced dermatoses of the face fulfilling the criteria for the study visiting the skin OPD in Tribhuvan University Teaching hospital over the study period were selected for the study after taking informed consent. Patients with rosacea and those denying the history of corticosteroid use were excluded. The demographic details of the patient were taken. A detailed history was taken and recorded in preformed questionnaire which included duration, class and indication of topical corticosteroids use. The source of the prescription and the class of the steroid used was recorded. A detailed history on the effects of steroids use which included pruritus, burning, photosensitivity (redness of face on exposure to sunlight), dryness and rebound phenomenon (flaring of lesions on withdrawal of topical corticosteroids) was recorded. A detailed examination of face was done by a dermatologist to see if there were comedones, erythema, papules, pustules, atrophy, telengiectasia, hypertrichosis and were recorded in the preformed structured questionnaire.

The study was approved by the Institutional Review Board (IRB) of Institute of Medicine and was carried out in accordance with the Code of Ethics of the World Medical Association.

\section{Results}

\section{Socio-demographic information}

There were 32 females and 7 males with a female to male ratio of $4.6: 1$. The median age of patients was 30 years (Age range 18 to 58 years). People with Mongoloids origins were the most common affected ethnic group (41\%) followed by Newars (17.9\%). Housewives were the most common groups affected (41\%) followed by Students (25.5\%) and self employed (12.8\%).

Most of the patients (38.5\%) abusing topical steroids were educated. Table 1 summarizes socio-demographic characteristics of the study participants.

\section{Steroid use}

The most common steroid used was class IV (48.1\%) followed by class V $(25.6 \%)$ and classes I and II ( $12.8 \%$ each). The median duration of topical corticosteroid abuse was 6 months and the maximum duration of its use was 96 months. About $33.3 \%$ of the patients used topical steroids intermittently for more than a year. All of them used steroid for dermatoses on their face which included melasma, eczemas of face, photodermatoses and acne. Most of them (38.5\%) used steroids after recommendation by their friends. Pharmacists (20.5\%) followed by over- the- counter purchase $(15.4 \%)$ contributed to the other sources of prescription. Of all these patients, the following effects of the long-term steroid use were seen: pruritus $(38.5 \%)$, burning $(15.4 \%)$, erythema $(74.4 \%$, Figure $1)$, telangiectasias (66.7\%), acneiform eruptions (59\%, Figure 2), comedones (35.9\%), xerosis (5.1\%), rebound phenomenon (38.5\%), photosensitivity (51.3\%), and others (38.5\%).

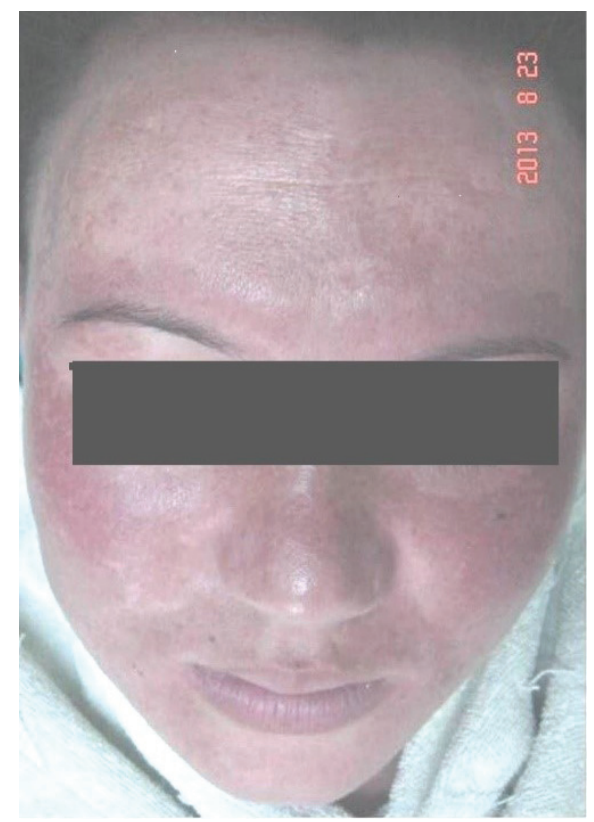

Figure 1: Steroid induced dermatoses. Erythema as a result of long- term abuse.

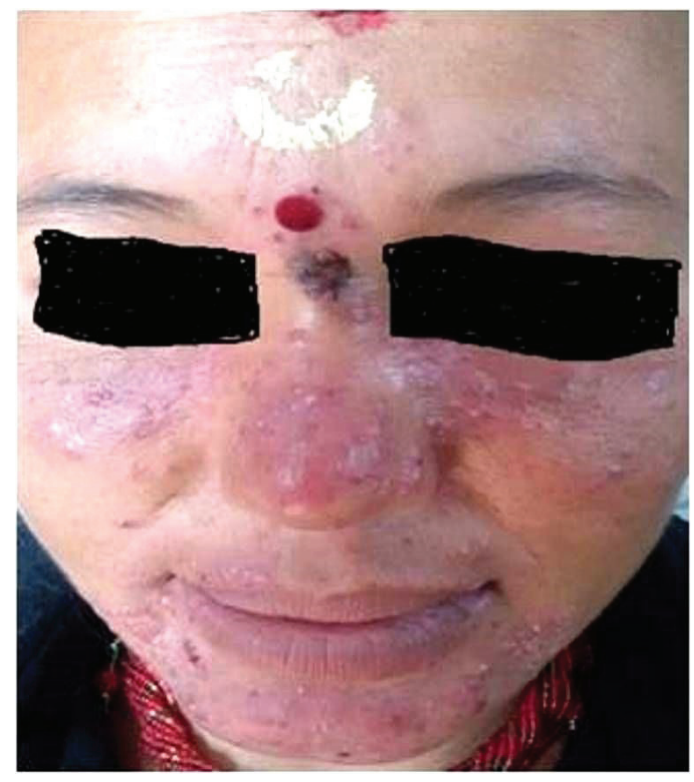

Figure 2: Steroid induced dermatoses. Papulo- pustules on face. 
Table 1: Socio-demographic characteristics of the participants. $n=39$

\begin{tabular}{|c|c|c|}
\hline Characteristics & Frequency & Percent \\
\hline \multicolumn{3}{|l|}{ Age group } \\
\hline $10-20$ & 6 & 15.4 \\
\hline $21-30$ & 15 & 38.5 \\
\hline $31-40$ & 11 & 28.2 \\
\hline $41-50$ & 6 & 15.4 \\
\hline $51-60$ & 1 & 2.6 \\
\hline \multicolumn{3}{|l|}{ Sex } \\
\hline Male & 7 & 17.9 \\
\hline Female & 32 & 82.1 \\
\hline \multicolumn{3}{|l|}{ Ethnic groups } \\
\hline Brahmin/Chhetris & 10 & 25.6 \\
\hline Newars & 7 & 17.9 \\
\hline Mongoloid & 16 & 41.1 \\
\hline Others & 6 & 15.4 \\
\hline \multicolumn{3}{|l|}{ Educational status } \\
\hline Illiterate & 11 & 28.2 \\
\hline Up to $10^{\text {th }}$ grade & 13 & 33.3 \\
\hline More than $10^{\text {th }}$ grade & 15 & 38.5 \\
\hline \multicolumn{3}{|l|}{ Occupational status } \\
\hline Housewives & 16 & 41.0 \\
\hline Students & 10 & 25.6 \\
\hline Self employed & 5 & 12.8 \\
\hline Office goers & 4 & 10.3 \\
\hline Others & 4 & 10.3 \\
\hline
\end{tabular}

Table 2: Distribution of topical steroid use and its characteristics. $n=39$

\begin{tabular}{|l|c|c|}
\hline Characteristics & Frequency & Percent \\
\hline Class of steroid used & 5 & 12.8 \\
II & 5 & 12.8 \\
IV & 19 & 48.7 \\
V & 10 & 25.6 \\
\hline Duration of topical steroid abused & & \\
(months) & & 53.9 \\
1-6 & 21 & 12.8 \\
7-12 & 5 & 33.3 \\
13 and above & 13 & 7.7 \\
\hline Source of Prescription & & 15.4 \\
Self & 3 & 20.5 \\
Over the counter & 6 & 7.7 \\
Pharmacist & 8 & 10.4 \\
Doctors other than Dermatologists & 3 & 38.5 \\
\hline Dermatologists & 4 & \\
Others (friends/family members) & 15 & \\
\hline
\end{tabular}

\section{Discussion}

Our study results showed that most of the patient abusing the topical corticosteroid included the adult population with a median age of 30 years (18 to 58 years) similar to another study done by Rathi SK et al. $^{6}$ This is the age when people seek advice to different types of health care providers along with the pharmacists and friends or family members for the treatment of their dermatoses and for cosmetic purpose. This population can easily be manipulated by different prescribers especially with the topical 
steroids which initially produce dramatic results for corticosteroid responsive dermatoses; however, this can result in steroid addictive dermatoses especially when the nature of disease is relapsing and remitting.

Females were found to be abusing corticosteroids compared to males, probably because they were more concerned about the affliction they had and that they were easily manipulated by the different source of prescribers.

People of Mongoloid origin were found to be affected more followed by Newars and other ethnic group. Most of the people with Mongoloid origin reside in the high hilly regions of Nepal where the UV exposure due to sun is supposed to be high. This might be reason for these people to be affected with the melasma and other dermatoses of the face which must have prompted them to misuse the topical steroid for the treatment of these dermatoses.

Housewives followed by students were found to be abusing the steroids compared to other occupation. Housewives must have been affected more because they must have been sufferers of dermatoses like melasma because of long duration of UV exposure compared with other occupation group; this could have prompted them to apply steroids.

Education did not seem to affect to reduce the abuse of topical steroid in our study. Most of the patients under study were found to be educated. Though the patients were educated, the reason behind the abuse could be the lack of knowledge on part of them regarding topical steroids.

These patients in our study had used steroids for long time with a median duration of use being 6 months and the longest duration of abuse was 96 months. Rathi SK et $\mathrm{al}^{6}$ and Bhat YJ et $\mathrm{al}^{7}$ in their study found the duration of steroid abuse to range from four months to 20 years and one month to 20 years respectively, longer compared to our population. This difference could be due to less number of patients in our study compared to them. Steroids resulted in disappearance of different dermatoses which made them to use this drug intermittently for long time. Moreover, patients had rebound effects when the drugs were stopped, which must have made them to use the drug again and again.

The most often abused steroid was class IV steroid because of its low cost and easy availability over the counter. The class of steroid abused has been found to be different in different studies. ${ }^{6,7}$ This could have been the result of difference in availability of topical steroids in different countries. Most of them had used the drugs on recommendation by their friends and relatives similar to that of another study by Hameed AF et al from Baghdad and the indication of use included melasma, acne, eczemas of face, and photodermatoses. ${ }^{8}$

The most common side effects of steroid abuse in our study was erythema and telangiectasia followed by acneiform eruptions, photosensitivity and rebound phenomenon. These results were the same as that found in other studies from India and China. ${ }^{6,7}$

Our study was conducted in a single centre of Nepal and the sample size was relatively small, hence, a larger study with longer duration will be needed in future to justify all the findings of this study. Nevertheless, the study is eye opener for all the fellow dermatologists to advocate for judicious use of topical steroid henceforth.

\section{Conclusion}

Steroid induced dermatoses were commonly seen in young people. The most common group to misuse the topical steroid was found to be housewives. The people of Mongoloid origin were the most common ethnic group to misuse the topical steroid. Class IV topical steroid was the most common group to be misused. The patients had been using steroid mainly for different dermatoses on their face. Family and friends of the patients were the ones who were prompting the use of the topical steroids. Erythema and telangiectasia were the most common side effects of the long-term use of topical corticosteroids. Policy makers should seriously consider solving this problem and can use these data for planning the rational drug use policy and to promote ethical use of topical steroids in Nepal.

\section{Acknowledgments}

We would like to thank Research Department, Institute of Medicine for their grant for performing this research.

Financial disclosure: The study was funded by the Research Department of Institute of Medicine, Maharajgunj, Tribhuvan University, Kathmandu, Nepal.

Conflicts of interest to disclosure: None declared.

The research paper was presented as poster in the $24^{\text {th }}$ European Academy of Dermatology and Venereology Congress, Copenhagen, Denmark, 7-11.10.2015. 


\section{References}

1. Velangi SS, Humphreys F, Beveridge GW. Periocular dermatitis associated with prolonged use of a steroid eye ointment. Clin Exp Dermatol. 1998;23:297-8. https://doi.org/10.1046/j.13652230.1998.00380.x

2. Hornstein OP. Perioral (rosaceiform) dermatitis - A 'modern' problem disease. Internist. 1975;16:278.

3. Lu H, Xiao T, Lu B, Dong D, Yu D, Wei H, et al. Facial corticosteroid addictive dermatitis in Guiyang City, China. Clin Exp Dermatol. 2010;35(6):618:21.

4. Kumar A, Neupane S, Shrestha PR, Pun J, Thapa $P$, Manandhar $M$, et al. Pattern and predictors of topical corticosteroid abuse on face: A study from western Nepal. RJPBCS 2015;6(3):1154-9.

5. Shakya SS, Bhandari M, Shrestha R, Thapa SR, Karki A, Prajpati $M$, et al. Study on corticosteroids

use pattern in dermatological practice and investigating adverse effect of corticosteroids including its associated factors. Kathmandu Univ Med J. 2015;51(3):261-7.

6. Rathi SK, Kumrah L. Topical corticosteroidinduced rosacea-like dermatitis: a clinical study of 110 cases. Indian J Dermatol Venereol Leprol. 2011;77(1):42-6. https://doi.org/10.4103/03786323.74974

7. Bhat YJ, Manzoor S, Qayoom S. Steroid - induced rosacea: A clinical study of 200 patients. Indian J Dermatol 2011;56:30-2. https://doi. org/10.4103/0019-5154.77547

8. Hameed AF. Steroid dermatitis resembling rosacea: a clinical evaluation of 75 patients. ISRN Dermatology. 2013;2013:491376. https://doi. org/10.1155/2013/491376. 